\title{
33. Data and analysis in social protection
}

\author{
Franziska Gassmann
}

\subsection{INTRODUCTION}

Policy analysis is the cornerstone of evidence-based policy making. ${ }^{1}$ It identifies the problems, informs programme design, supports the monitoring of policy implementation and is needed to evaluate programme impacts (Scott 2005). Rigorous and credible policy evidence is necessary to ensure the transparency and accountability of policy decisions, to secure political and public support and, hence, the allocation of financial resources. Sound policy analysis helps design effective and efficient programmes, thereby maximizing programme impact.

Recent decades have seen a steady rise in social protection investments both by national governments and international development partners. Social protection systems are recognized as strategies that can effectively address poverty and inequality, which is reflected in the inclusion of social protection in many national and international development strategies, including the Sustainable Development Goals (SDGs) (UN 2015). Given the variety of actors involved in the design, delivery and financing of social protection programmes at local, national and global levels, the use of statistics, data and social protection performance indicators is essential for the effective collaboration between these actors (Bonnet and Tessier 2013).

Data on social protection coverage, benefit levels and financing are critical for the analysis of social protection within and across countries (Bonnet and Tessier 2013). In addition, regular monitoring and evaluation provide evidence on the impact, effectiveness and best practices in social protection while contributing to re-enforcing the political will to sustain or scale up social protection initiatives (OECD 2019). At the global level there is a variety of social protection performance indicators available from different actors. Yet, indicators vary in terms of definition, methodological specification and data source used, which limits the comparability and complicates monitoring and analysis of social protection systems (European Commission 2017; OECD 2019).

This chapter takes stock of the existing conceptual frameworks, methods, databases and indicators used to evaluate social protection performance. It starts with presenting an overview of the conceptual frameworks around social protection, establishes the role of performance measurement in social protection and discusses the challenges of current databases and indicators in effectively measuring the performance of social protection systems.

\subsection{CONCEPTUAL OVERVIEW}

Different actors have different perspectives and policy priorities associated with social protection. Policy priorities are shaped by many different factors including the extent of needs,

1 The author would like to thank Anand Ramesh Kumar for his excellent research assistance. 
the socio-economic context and political and civil society priorities (European Commission 2017). The conceptual frameworks around social protection are inspired by different ideological contexts. Key examples include the World Bank's Social Risk Management Framework (World Bank 2003), Devereux and Sabates-Wheeler's Transformative Social Protection (Devereux and Sabates-Wheeler 2004) and the International Labour Organization's (ILO) Life Cycle approach to social protection (Garcia and Gruat 2003). The global narrative on social protection has increasingly aligned to a human rights-based approach, aiming to address vulnerabilities of individuals across the life cycle and contributing to inclusive pro-poor growth (European Commission 2017).

The understanding of the term 'social protection' varies across different stakeholders. ${ }^{2}$ But irrespective of the definition used, they all encompass three key dimensions: they address risk and vulnerability, levels of deprivation deemed unacceptable and a form of response that is both social and public in nature. This chapter adopts ILO's broader definition of social protection, which describes it as 'a set of policies and programmes designed to reduce and prevent poverty and vulnerability across the life cycle' (ILO 2017a, 2). This definition includes a range of policy areas including child and family benefits, maternity protection, unemployment support, employment injury benefits, health protection, old-age benefits, disability benefits and survivor benefits (ILO 2017a). It encompasses both the absolute deprivation of the poorest and the needs of the non-poor to cope with vulnerabilities at different stages of life (Norton et al. 2001), and includes both private and public interventions. Social protection policies and programmes are traditionally organized along two main categories: contributory social insurance and non-contributory tax-financed social assistance (ILO 2017a). Other international agencies including the World Bank (Yemtsov et al. 2018), the Asian Development Bank (ADB 2013) and the European Commission (2017) have expanded this basic classification by explicitly including social services and labour market policies as separate categories of social protection interventions.

The subtle differences in the definition of social protection and classification of policy interventions between international agencies leading the social protection discourse result in a multitude of data points and indicators which are not necessarily comparable. In an effort to streamline the conceptual underpinning of social protection, the international development community has adopted overarching frameworks that reflect the conceptual evolution and current understanding of the concept. The Social Protection Floor is such an example. It features in SDG 1 (UN 2015). Other initiatives, such as the establishment of the Social Protection Inter-Agency Cooperation Board (ILO 2012) in 2012, aim to strengthen the institutional collaboration and contribute to an improved coordination of international efforts to establish social protection systems in member states.

\footnotetext{
2 Differences exist between broad and narrow, between nature of the problem/deprivation addressed and policy instruments used to address the deprivation and between conceptual and pragmatic approaches adopted (Norton et al. 2001).
} 


\subsection{PERFORMANCE MEASUREMENT IN SOCIAL PROTECTION}

Performance measurement to assess how well a policy or programme achieves its objectives is an integral part of any policy design. Focusing on performance implies a move away from the traditional focus on input (budget allocation) to outputs, outcomes and impacts (Gassmann 2010). Performance measurement extends well beyond the economic implications of social protection policies (Delorme and Chatelain 2011). Social protection, whether provided by governmental or non-governmental actors, is considered a public good or service intended to produce specific outcomes for the society. Given the complex linkages and interdependencies, the observable societal impact is the result of numerous interactions, and not just of one policy measure or social behaviour (Delorme and Chatelain 2011). The complexity of the political and socio-economic landscape wherein social protection programmes operate creates a challenge to isolate programme effects from other influencing factors.

Effective performance measurement implies that at programme level, there needs to be a clear identification of factors contributing to input, output, outcome and impact, and their associated indicators. Considering the public nature of social protection, market competition, which is a critical factor contributing to price correction and quality of service, is mostly absent in the sector (Gassmann 2010). Hence, regular policy monitoring and performance measurement is the only tool to ensure programme effectiveness and efficiency in the social protection sector (European Commission 2017).

Performance measurement frameworks are often riddled with complications. The quality of performance measures depends on the strength, quality and representativeness of the underlying frameworks, indicators and databases. Bonnet and Tessier (2013), in their analysis of international statistics and indicators, point out that globally, there is a lack of consistent and comparable methodologies for analysing social protection outcomes across countries. At the national level, the availability of social protection data is often fragmented with the quality of data varying across countries, and across programmes and schemes within countries. The challenges at the national level are also reflected at the global level, given existing data gaps and inconsistencies across databases. Moreover, measuring and quantifying qualitative aspects of social protection performance is time-consuming and costly, and often requires specific information rarely captured in quantitative surveys.

\subsubsection{Theories of Change and Results-Oriented Frameworks}

Prominent actors leading the social protection discourse advocate for a results-oriented framework for performance measurement (Gassmann 2010). Results-oriented frameworks are explicit articulations of different stages, levels and chains of results expected from an intervention. The result specifications include both long-term results (often referred to as impact or outcome) and medium- and short-term results (often referred to as output) (World Bank 2012).

A typical results-oriented framework allows for the classification of indicators into five key dimensions: input indicators, process indicators, output indicators, outcome indicators and impact indicators (European Commission 2017). Figure 33.1 shows an example of a results-oriented framework. Input indicators and process indicators account for the financial, administrative and regulatory resources utilized to implement a particular programme (Delorme and Chatelain 2011). These indicators are useful to quantify the supply side of social 
protection interventions. On the other hand, output indicators, outcome indicators and impact indicators help quantify the results. While results-oriented frameworks provide a useful lens for the evaluation of social protection programmes, the validity of the framework depends on the strength of the underlying theory of change. Figure 33.2 provides an example of how such a results framework can be used for the identification of indicators for a cash transfer programme.

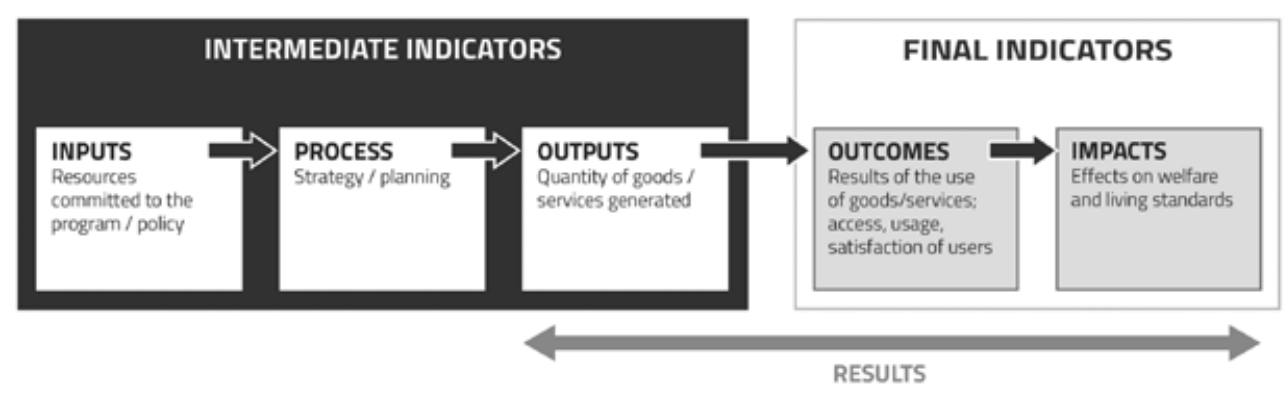

Source: Author's own illustration based on Gassmann (2010) and European Commission (2015).

\section{Figure 33.1 Result-oriented evaluation framework}

Theories of change can be understood as the logic linking programme input and the intended impact (ILO 2017b), and can be represented as system diagrams, log frames or other visual representations. The theory of change conveys the logical pathway along which an intervention is expected to achieve results. A well-conceptualized theory-of-change model identifies contributors and barriers to change allowing policy analysts to focus on whether, how and why these factors achieve social change (ILO 2017b).

In the context of social protection, theories of change and results-oriented frameworks provide a roadmap through broader theoretical frameworks (and complex political and

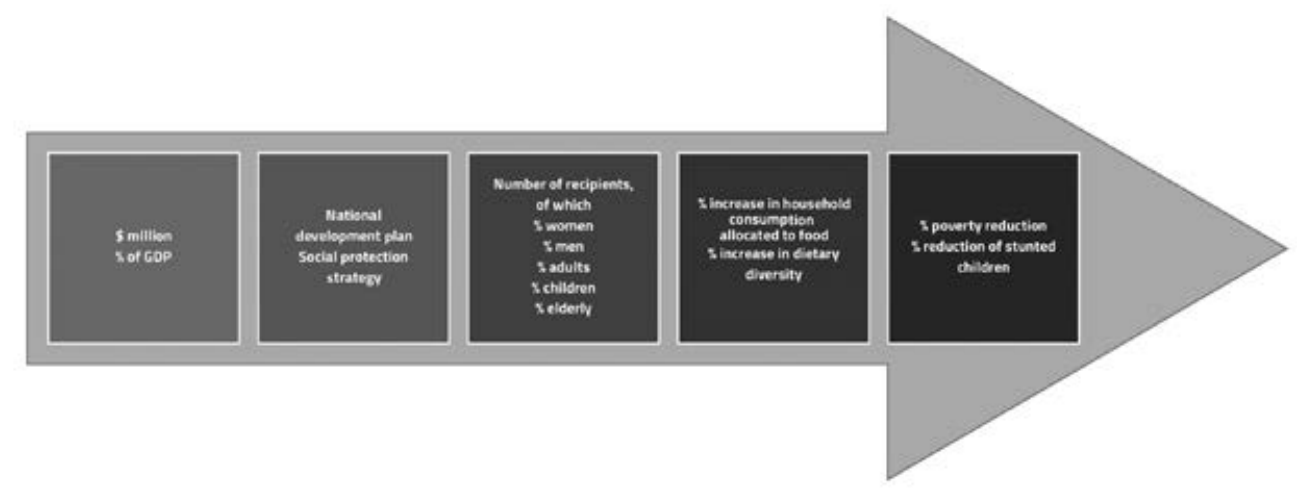

Source: Author's own illustration.

Figure 33.2 Example of a results-oriented framework for cash transfers 
socio-economic contexts) that underpin social protection interventions. These conceptual tools support programme planning and design and play an essential role in the monitoring and evaluation of these programmes. They support the design of specific evaluation questions, identifying relevant variables that should be included in the data collection, identifying relevant intermediate outcomes that can determine success of interventions and identifying aspects of intervention that should necessarily be included in the evaluation. They facilitate testing the validity of assumptions that connect various elements of social protection policy design (Rogers 2014).

\subsubsection{Indicators and Databases for Social Protection}

The analysis of social protection performance relies on the selection of appropriate indicators and data that allow measuring these indicators. An indicator is defined as an order of magnitude (generally statistical, but also logical) linked naturally (or arbitrarily) to the measurement of policy activities. Indicators are characterized by their function (what it measures), the means through which they are obtained (formula, calculations or necessary data points), their quality (the extent to which they can be interpreted and monitored over time) and the limits on their use (what it does not measure, or measures poorly) (Delorme and Chatelain 2011).

Performance indicators help assess how well a programme or intervention achieves its objectives. Cichon et al. (2004) differentiate between two types of performance indicators: (1) indicators to assess the process that converts inputs into outputs, and (2) indicators that assess outcomes which indicate the degree of desired social change achieved by the programme. Research on social protection indicators has gained a lot of momentum over the last few decades. The European Commission (2017), for example, suggests five key stages in the appraisal of social protection indicators: (1) the definition of social protection adopted, (2) identification of targets and objectives, (3) choice of type of indicators and data sources, (4) appraisal of indicator performance and (5) the assessment of indicator comparability (European Commission 2017). The choice of indicators reflects the specific definitions and objectives of the respective social protection intervention being evaluated.

Good indicators share a number of features (Gassmann 2010). They are not only SMART (specific, measurable, achievable, realistic and time-bound), ${ }^{3}$ but include intelligent benchmarks, which are essential for the interpretation of indicators with respect to performance (Cichon et al. 2004). While some indicators may permit a stand-alone interpretation of performance (for example coverage rates), others (for example demographic ratio) do not allow for such an interpretation.

\subsubsection{Comparative Social Protection Indicators and Datasets}

Today, a range of global and regional agencies collate information on social protection from around the world. Conceptual differences in the definition of social protection across agencies makes it very challenging, if not impossible, to combine or compare information from different sources. Table 33A.1 in the appendix to this chapter lists indicators and databases from

\footnotetext{
3 There is an extensive literature on the desirable qualities of indicators. See, for example, Cichon et al. (2004), Zall Kusek and Rist (2004), Castro (2011) and European Commission (2017).
} 
major agencies involved in social protection. ${ }^{4}$ Though not comprehensive, the table gives an impression of the type of social protection indicators collected by international and regional agencies. Current indicator clusters and databases are primarily input and output biased, with limited indicators contributing to measure outcome or impact (European Commission 2017). Most of the agencies also collect programme-specific indicators for countries where they operate. These indicators are reflected in the respective results frameworks, log frames and project appraisal documents adopted by these agencies (European Commission 2017), but they are rarely available to the public.

While the majority of indicators reflect a single input, output or outcome, some agencies have developed composite indicators or indices that can facilitate comparison of social protection performance for a region or a set of countries. The Asian Development Bank's Social Protection Index (SPI) (ADB 2013) is a relatively straightforward composite indicator that divides total expenditures on social protection by the total number of intended beneficiaries of all social protection programmes. The SPI is currently available for 35 countries in the Asia-Pacific region. It allows for disaggregation based on programme type (social insurance, social assistance or labour market programmes), gender, depth (average size of benefit received) and breadth (proportion of intended beneficiaries actually receiving benefit) (ADB 2013). Similarly, the Global Coalition for the Social Protection Floor developed the Social Protection Floor Index (Bierbaum et al. 2017), which is a composite indicator measuring the financial resources a country requires to provide a national social protection floor. The Social Protection Floor Index has been developed with the vision to contribute to monitoring progress towards the SDGs by offering a comparative scale to measure social protection performance for over 120 countries across the world. ${ }^{5}$

\subsection{TOOLS AND METHODS FOR MEASURING IMPACT}

The review of indicators currently used at global or regional level has shown that the focus is primarily on intermediate indicators and a few outcomes. The World Bank and the ILO, for example, regularly publish reports on the state of social protection in the world. The World Bank's The State of Social Safety Nets uses the Atlas of Social Protection Indicators of Resilience and Equity (ASPIRE) as the main data source. The chapter on the performance of social protection programmes also provides estimates of programme impact on poverty and inequality (see, e.g. World Bank 2018). It is a heroic, yet rudimentary, attempt to measure and compare impacts and go beyond the usual inputs and outputs. Yet, in order to measure programme-level impacts and establish causality, more in-depth analysis is required with additional tools and data. The choice of evaluation methodology is often tailor-made for a particular programme and is ideally guided by a carefully constructed theory-of-change model that established the causal linkages between inputs and outcomes and impact. Hence, impacts are not directly comparable across studies. Systematic reviews fill that gap by trying to distil

4 For the purpose of this chapter, we consider only databases that are representative of substantial regional or global aggregations and that compile large-scale data on social protection. Only selected indicators are included. For the full sets of indicators, we refer readers to the original sources.

5 Social protection features in four (five, if health is included as well) of the 17 SDGs (UN 2015). 
general conclusions from a multitude of impact studies. ${ }^{6}$ Evidence and gap maps categorize and visualize the available evidence. ${ }^{7}$

Frequently used methodologies to assess programme impact include experimental methods (randomized control trials (RCTs)), quasi-experimental methods and microsimulations (for ex ante evaluations) (OECD 2019). Experimental methods, particularly RCTs, rely on the ability to randomize treatment among eligible beneficiaries. Non-recipients serve as a control group against which impact is measured. The average treatment effect (ATE) is determined by comparing the two groups on selected outcome and impact indicators (White et al. 2014). Often referred to as the gold standard for impact assessment, if implemented properly, RCTs can provide robust estimates of programme impact (OECD 2019). However, experimental methods are not always feasible. RCTs are difficult to implement in cases where causal pathways are not effectively identified (White et al. 2014). RCTs have to be planned prior to the beginning of the intervention and as such are best used in a pilot setting. In order to provide statistically robust data, the sample size needs to be large enough to effectively determine programme impact and ensure internal validity. RCTs raise concerns about their external validity (Deaton and Cartwright 2018) and are sometimes challenged on ethical grounds. In a recent systematic review of the impacts of cash transfer programmes covering publications from 2000 to 2015, 58 per cent of the included studies used some type of RCT to measure impact, and 42 per cent used quasi-experimental methods (Bastagli et al. 2016).

RCTs are increasingly used in the field to assess the impact of social protection initiatives. For example, Banerjee et al. (2015) present results from six RCTs conducted in different geographical and institutional contexts. In a combined effort across six countries (Ethiopia, Ghana, Honduras, India, Pakistan and Peru), a multifaceted graduation programme ${ }^{8}$ was designed to improve the livelihoods of the poorest households by fostering self-employment activities. The findings demonstrate the lasting impact of a relatively short-term multifaceted programme for the very poor. Ten key outcomes were measured for programme effect and the results of the study allow for the conclusion that a multifaceted approach to increasing income and wellbeing for the ultra-poor is both sustainable and cost-effective (Banerjee et al. 2015).

Quasi-experimental methods use statistical methods to synthetically construct a credible comparison group, but there is always a chance that treatment and control groups differ in ways that cannot be observed and which are not the result of programme participation (OECD 2019), but which may affect the outcomes of interest. Matching is a commonly used quasi-experimental method to statistically establish a control group based on observable characteristics. The methodology relies on the assumption that programme participation and the intended impact are not influenced by any unobserved characteristics (OECD 2019). When panel data are available, for example from two survey rounds, difference-in-difference (DiD)

\footnotetext{
6 See, for example, Bastagli et al. (2016) for a more recent and very comprehensive systematic review of cash transfer impacts.

7 The Campbell Foundation is currently developing an evidence and gap map on social protection (campbellcollaboration.org/evidence-gap-maps.html, see Case study Q in this handbook). Also see 3ieimpact.org/evidence-hub/evidence-gap-maps for evidence and gap maps on related topics.

8 Graduation programmes go beyond the provision of transfers in cash or in kind by offering households additional services and support. In the case of Banerjee et al., '[t] he programme targets the poorest members in a village and provides a productive asset grant, training and support, life skills coaching, temporary cash consumption support, and typically access to savings accounts and health information or services' (Banerjee et al. 2015, 772).
} 
methods, where the ATE is deduced by comparing treatment and control groups over time, can be used (OECD 2019). DiD assumes that the characteristics of treatment and control groups do not evolve differently over time. DiD can also be combined with matching. Regression discontinuity design is another commonly used method, whereby the ATE is estimated around a cut-off point usually inspired by the programme itself, such as an age limit in the case of an old-age pension or a score used for poverty targeting. Regression discontinuity design utilizes the programme-driven discontinuity as a means to estimate the ATE assuming that there are no systematic differences for programme participation (OECD 2019). In the end, '[w] hat methods are best to use and in what combinations depends on the exact question at stake, the kind of background assumptions that can be acceptably employed, and what the costs are of different kinds of mistakes' (Deaton and Cartwright 2018, 2).

Stakeholders often use a combination of different quasi-experimental methods for the assessment of programme impacts. For example, four out of five impact evaluations in the special issue of the Journal of Development Studies on social protection in the contexts of fragility and forced displacement (Brück et al. 2019) use a quasi-experimental design. The evaluation of the Leap 1000 programme in Ghana (de Groot 2016) or the SAGE programme in Uganda (see, for example, Merttens et al. 2016) have used a quasi-experimental design. Reviewing the evaluation repository of the International Initiative for Impact Evaluation's 264 evaluations related to social protection have been published since 2010 using a quasi-experimental design.

Ex ante impact assessments are used to inform policy planning and decision making. Microsimulations are tools for ex ante evaluations allowing for the assessment of different scenarios on expected policy impact. Microsimulations often use large-scale data aggregations and are driven by the validity and reliability of their underlying models, conceptual rules and assumptions (OECD 2019). The robustness of microsimulations can be improved by modelling additional layers of complexity to replicate multiple levels of programme impact. They allow testing deterministic aspects like benefit size against specific individual or household characteristics. Microsimulations are powerful tools for policy makers to undertake cost to impact assessment of various policy options to a social protection design (OECD 2019). Prominent examples include EUROMOD, which is a tax-benefit microsimulation model for the European Union (EU) 'that enables researchers and policy analysts to calculate, in a comparable manner, the effects of taxes and benefits on household incomes and work incentives for the population of each country and for the EU as a whole' (www.euromod.ac.uk/about/what-is-euromod); ${ }^{9}$ or the ILO Pension Model for the actuarial assessment of future pension developments and financing methods (ILO 2018). More recently, attempts have been made to estimate rates of return to social protection using microeconometric models and by comparing future costs and benefits of alternative social protection interventions (see, for example, Mideros et al. 2016; Dietrich et al. 2019).

\footnotetext{
9 EUROMOD is currently extended to SOUTHMOD. See: wider.unu.edu/project/southmod -simulating-tax-and-benefit-policies-development.
} 


\subsection{CHALLENGES WITH EXISTING SOCIAL PROTECTION DATA AND INDICATORS}

Even though there are a wealth of social protection indicators currently available, the comparability across different databases remains a challenge. As indicated above, the selection of social protection performance indicators is heavily influenced by how data holders define and conceptualize social protection. The ILO, Organisation for Economic Co-operation and Development (OECD) and the EU, for example, classify social protection programmes on the basis of the functions of social protection (sickness, old age, disability, etc.) and the corresponding risks they address. The World Bank and the Asian Development Bank, on the other hand, classify social protection by type (social insurance, social assistance and labour market programmes) (European Commission 2017). As a result, data from different sources cannot be combined in order to increase, for example, the number of observations or time periods for statistically robust analyses across countries. Moreover, conclusions may differ depending on the data depository used. A prominent example is government expenditures on social protection. The lack of a common (minimum) standard means that totals differ per country (and programme) and data source.

Another challenge relates to the type of indicators currently available. As discussed above, performance measurement requires indicators covering the different stages of the results chain. These indicators should also satisfy a range of quality properties. But currently propagated social protection indicators have a strong input bias (European Commission 2017). These indicators are mainly available at country level and rarely provide disaggregated information for population groups, such as by age, sex or location. Keeping in mind the fact that social protection interventions are often targeting specific population groups, the lack of disaggregated data makes it difficult to assess programme outcomes for different groups of beneficiaries. Existing social protection indicator data collections have very limited outcome and impact indicators (European Commission 2017). The World Bank ASPIRE database is an exception. It contains a number of outcomes (for example, transfer adequacy) and basic impact indicators (for example, poverty and inequality rates before and after transfers).

National household surveys play an important role in the global social protection data landscape, but they also present a challenge for the standardization of indicators. Many of the aggregate social protection databases use national household surveys as a key source (see Table 33A.1). These surveys are often the only source to measure household wellbeing and the impact of social protection programmes on poverty, inequality and other human development outcomes. Research indicates that many household surveys have limited or no questions pertaining to specific social protection programmes, benefit levels or adequacy (Bonnet and Tessier 2013). The usefulness of household surveys in the context of social protection policy evaluations could be further strengthened by collecting data more frequently and including specific modules on social protection programmes in survey questionnaires. The United Nations Children's Fund (UNICEF), through the Multiple Indicator Cluster Surveys (MICS), is supporting most low- and middle-income countries in the production of statistically sound and globally comparative data on women and children. In order to improve the available data on social protection, UNICEF has developed and tested a set of questions related to social protection for inclusion in future MICS rounds (Moore et al. 2018).

Qualitative data are necessary to provide contextual information on social protection (European Commission 2017; Devereux et al. 2013). This includes information on behav- 
ioural and institutional mechanisms and changes that may otherwise be difficult to quantify. Currently, there is a lack of reliable qualitative information on social protection systems (Bonnet and Tessier 2013). Indicators like social protection expenditure, which are predominantly used today to compare social protection performance of countries convey only one side of the social protection story. The effectiveness and efficiency of social protection systems are heavily dependent on the social and institutional contexts in which they operate. Conventional indicators do not cover programme processes or feedback loops (Devereux et al. 2013). Without this information, the comparison of standardized social protection indicators may present rather simplified measures of performance that do not reflect the realities on the ground.

Several organizations have tried to find ways to harmonize national social protection data as a means to address some of the challenges of existing data. Some suggest that the way forward is through a nationally integrated digital social protection management information system (MIS) (GIZ 2019). A MIS could form the backbone for social protection data aggregation, facilitating a harmonized social protection approach across countries. The implementation of such systems requires high-level collaborations and joint planning between various stakeholders involved in the social protection landscape of countries with clear identification of the data needs of each user (GIZ 2019). Such an integrated approach to social protection data management at the national level could potentially improve the data quality in global social protection databases.

Big data is the new buzzword. It could offer innovative ways of combining and utilizing existing data. ${ }^{10}$ There is a wealth of information in administrative databases, which are not accessible due to privacy concerns. However, recent technological innovations have facilitated the interoperability of such data sources making big data increasingly feasible in the social protection sector (Gillingham and Graham 2016). A notable example is the research undertaken at Chapin Hall in Chicago, United States. Chapin Hall partners with all levels of government, non-profits and researchers, acting as a steward of administrative data collectively utilized to address challenges facing children, youth and families in the United States and beyond (Chapin Hall 2013). Similarly, a pilot project in Heerlen, Netherlands combines data from Statistics Netherlands, the social service administration of the municipality, and data from the major health insurance provider in the region. The objective is to get a better understanding of poverty in the municipality and identify factors that can predict poverty before it actually happens, and without revealing any sensitive data, thereby preserving the privacy of individuals. ${ }^{11}$ While this may be out of reach for many low-income countries, the available administrative and survey data are increasing everywhere. In the future, machine-learning could potentially be used to utilize the data for both research and policy design.

\subsection{CONCLUSIONS}

'Development is not a science - it is a struggle to try to improve the human condition, but a struggle in which we are denied the ultimate reassurance of knowing whether we were suc-

10 gapmaps.3ieimpact.org/evidence-maps/big-data-systematic-map visualizes the use of big data in the analysis of various development outcomes.

11 For more information on the project, see www.techruption.org/usecase/poverty/. 
cessful, or not,' writes Michael Kleinman (2017). Considering the spectrum of factors affecting the impact of social protection policies and programmes, measuring their performance will always remain a challenge. It is also evident that this task cannot be limited to a handful of development agencies working in a disaggregated manner, but requires the inclusion of all stakeholders, including national government agencies, research institutes, think tanks and academia.

The effective utilization of resources is critical for the achievement of the SDGs. In the context of social protection, this translates into effective designing, planning, implementing and monitoring social protection programmes. Quality, reliable and timely data play a role in each stage. In the current scenario, it could be inferred that no one indicator cluster used to monitor social protection performance conveys the complete picture. Taking into consideration practical modalities associated with institutional mandates, definitions used and data availability, no single framework of indicators may be up to the task. But the increasing recognition of social protection as a global mandate ensures that today we have more actors involved in the delivery of social protection than ever before in history. It could be inferred then that the degree of collaboration between these actors will determine the robustness of social protection data available to actors involved in monitoring and evaluation.

Harmonization of data should be a mandate under collaborative initiatives like the Social Protection Inter-Agency Cooperation Board. A minimum set of core data needs should be identified and its collection universally facilitated as mandatory components of any developmental support offered by the international community (Gassmann 2010). Harmonization at the country level is also key to this process. Mapping data requirements for social programming should also be done at the country level. While these steps do not ensure the robustness of data, they have the potential to better inform social protection design and performance measurement for national and international actors in the future.

Social protection goes beyond the treatment of residual human welfare problems. As a policy sector it does not operate in a vacuum but is closely linked with other policy sectors. It has the potential to protect and promote the human potential while ensuring equality of opportunity and outcome (Norton et al. 2001). The complexity of the political and socio-economic web in which social protection operates makes it a daunting task to deduce its impact or outcomes. Hence, indicators, databases and data sources used to measure and analyse the impact of social protection interventions have to reflect this complexity to effectively convey their impact.

\section{REFERENCES}

ADB (2013). The Social Protection Index: Assessing Results for Asia and the Pacific. Manila: Asian Development Bank. www.adb.org/publications/social-protection-index-assessing-results-asia-and -pacific

Banerjee, A., E. Duflo, N. Goldberg, D. Karlan, R. Osei, W. Parienté, J. Shapiro, J. Thuysbaert and C. Udry (2015). A multifaceted programme causes lasting progress for the very poor: Evidence from six countries. Science 348 (6236). https://doi.org/10.1126/science.1260799

Bastagli, F., J. Hagen-Zanker, L. Harman, V. Barca, G. Sturge and T. Schmidt (2016). Cash transfers: What does the evidence say? A rigorous review of programme impact and of the role of design and implementation features. London: Overseas Development Institute. www.odi.org/sites/odi.org.uk/ files/resource-documents/10749.pdf

Bierbaum, M., C. Schildberg and M. Cichon (2017). Social Protection Floor Index: Update and Country Studies. Berlin: Friedrich Ebert Foundation. http://library.fes.de/pdf-files/iez/13973.pdf 
Bonnet, F. and L. Tessier (2013). Report on the workshop 'Mapping existing international social protection statistics and indicators that would contribute to the monitoring of social protection extension through social protection floors', Geneva, Switzerland, 13th-15th March 2013. ESS Working Paper No. 38. Geneva: International Labour Organization. www.social-protection.org/gimi/gess/ RessourcePDF.action? ressource.ressourceId $=39717$

Brück, T., J. Cuesta, J. De Hoop, U. Gentilini and A. Peterman (2019). Social protection in contexts of fragility and forced displacement: Introduction to a special issue. Journal of Development Studies 55 (sup1), 1-6. https://doi.org/10.1080/00220388.2019.1687882

Castro, M.F. (2011). Defining and using performance indicators and targets in government M\&E systems. PREM Notes, Number 12. Washington, DC: World Bank.

Chapin Hall (2013). Our Capabilities. Chicago: University of Chicago: www.chapinhall.org/history/our -capabilities/

Cichon, M., W. Scholz, A.V. Meerendonk, K. Hagemejer, F. Bertranou and P. Plamondon (2004). Financing Social Protection. Geneva: International Labour Organization.

de Groot, R. (2016). Ghana LEAP 1000 impact evaluation: Overview of study design. Innocenti Research Briefs no. 2016-01. Florence: UNICEF Office of Research - Innocenti.

Deaton, A. and N. Cartwright (2018). Understanding and misunderstanding randomized controlled trials. Social Science and Medicine 210, 2-21.

Delorme, P. and O. Chatelain (2011). Policy Steering: The Role and Use of Performance Measurement Indicators. Brussels: European Commission and Europe Aid.

Devereux, S. and R. Sabates-Wheeler (2004). Transformative social protection. IDS Working Paper 232. Brighton: Institute of Development Studies.

Devereux, S., K. Roelen, C. Béné, D. Chopra, J. Leavy and J.A. McGregor (2013). Evaluating outside the box: An alternative framework for analysing social protection programmes. IDS Working Paper 431. Brighton: Institute of Development Studies.

Dietrich, S., D. Malerba, A. Barrientos, F. Gassmann, P. Mohnen and N. Tirivayi (2019). Human capital returns to cash transfers in Uganda: Does it matter in the long run? Journal of Development Effectiveness 12 (1), 54-73.

European Commission (2015). Commission Staff Working Document: Launching the EU International Cooperation and Development Results Framework. SWD (2015) 80. Brussels: European Commission.

European Commission (2017). Indicators to Measure Social Protection Performance: Implications for EC programming. Tools and Methods Series Concept Paper No. 5. Brussels: European Commission.

European Commission (2020). Social Protection (ESSPROS): Overview. Brussels: European Commission. https://ec.europa.eu/eurostat/web/social-protection/overview

Garcia, A. and J. Gruat (2003). Social Protection: A Life Cycle Continuum Investment for Social Justice, Poverty Reduction and Sustainable Development. Geneva: International Labour Organization.

Gassmann, F. (2010). Performance Measurement for Social Protection. Note commissioned by DG EuropeAid, E3/ESIP. Brussels: European Commission.

Gillingham, P. and T. Graham (2016). Big data in social welfare: The development of a critical perspective on social work's latest 'electronic turn'. Australian Social Work 70 (2), 135-47.

GIZ (2019). Building an integrated and digital social protection information system. Bonn: Deutsche Gesellschaft für Internationale Zusammenarbeit. www.giz.de/de/downloads/giz2019-en-integrated -digital-social-protection-information-system.pdf

ILO (2012). Social Protection Inter-Agency Cooperation Board. Geneva: International Labour Organization. www.ilo.org/newyork/at-the-un/social-protection-inter-agency-cooperation-board/lang --en/index.htm

ILO (2017a). World Social Protection Report 2017-19: Universal Social Protection to Achieve the Sustainable Development Goals. Geneva: International Labour Organization.

ILO (2017b). Theory of Change. I-eval Resource Kit Guidance Note 1. Geneva: International Labour Organization.

ILO (2018). The ILO Pension Model: A Technical Guide. Geneva: International Labour Organization.

ILO (2020). Social Protection Floors Initiative. Geneva: International Labour Organization. www.social -protection.org/gimi/ShowProject.action?id=2767 
Kleinman, M. (2017). Development is not a science and cannot be measured. That is not a bad thing. The Guardian, 1 June. www.theguardian.com/global-development-professionals-network/2017/jun/01/ development-is-not-a-science-and-cannot-be-measured-that-is-not-a-bad-thing

Merttens, M., E. Sindou, A. Lipcan, L. Pellerano, M. Binci, S. Ssewanyana, S. Neema, R. Attah, S. Otulana, C. Hearle and S. Garbarino (2016). Evaluation of the Uganda Social Assistance Grants for Empowerment (SAGE) programme: Impact after two years of programme operations 2012-2014. Final report. Oxford: Oxford Policy Management.

Mideros, A., F. Gassmann and P. Mohnen (2016). Estimation of rates of return on social protection: Ex-ante microsimulation of social transfers in Cambodia. Journal of Development Effectiveness 8 (1), $67-86$.

Moore, Z., C. Suzuki and P. Idele (2018). Developing a household survey instrument on social protection. MICS Methodological Papers, No. 8. New York: United Nations Children's Fund. https://mics.unicef.org/files?job=W1siZiIsIjIwMTgvMTEvMDgvMjIvNDcvMTcvMzQ0L01JQ1N fTWV0aG9kb2xvZ2ljYWxfUGFwZXJfOC5wZGYiXV0\&sha=e425257d39e5f9ad

Norton, A., T. Conway and M. Foster (2001). Social protection concepts and approaches: Implications for policy and practice in international development. Working Paper 143. London: Overseas Development Institute.

OECD (2019). Monitoring and Evaluating Social Protection Systems: Lessons from the EU-SPS Programme. Paris: Organisation for Economic Co-operation and Development.

Rogers, P. (2014). Theory of Change. Florence: UNICEF Office of Research - Innocenti.

Scott, C. (2005). Measuring Up to the Measurement Problem: The Role of Statistics in Evidence-Based Policy-Making. Paris: Organisation for Economic Co-operation and Development. https://paris21.org/ sites/default/files/1509.pdf

UN (2015). About the Sustainable Development Goals. New York: United Nations. www.un.org/sus tainabledevelopment/sustainable-development-goals/

White, H., S. Sabarwal and T. de Hoop (2014). Randomized Controlled Trials (RCTs). Florence: UNICEF Office of Research - Innocenti.

World Bank (2003). Social Risk Management: The World Bank's Approach to Social Protection in a Globalizing World. Washington, DC: World Bank. http://documents.worldbank.org/curated/en/ 494981468762925392/Social-risk-management-The-World-Banks-approach-to-social-protection-in -a-globalizing-world

World Bank (2012). Designing a Results Framework for Achieving Results: A How-To Guide. Washington, DC: World Bank. http://documents.worldbank.org/curated/en/331541563854787772/ Designing-a-Results-Framework-for-Achieving-Results-A-How-to-Guide

World Bank (2018). The State of Social Safety Nets 2018. Washington, DC: World Bank. https://doi:10 $.1596 / 978-1-4648-1254-5$

Yemtsov, R., M. Honorati, B. Evans, Z. Sajaia and M. Lokshin (2018). Measuring the Effectiveness of Social Protection: Concepts and Applications. Streamlined Analysis with ADePT Software Series. Washington, DC: World Bank. https://doi:10.1596/978-1-4648-1090-9

Zall Kusek, J. and R.C. Rist (2004). Ten Steps to a Results-Based Monitoring and Evaluation System: A Handbook for Development Practitioners. Washington, DC: World Bank. 


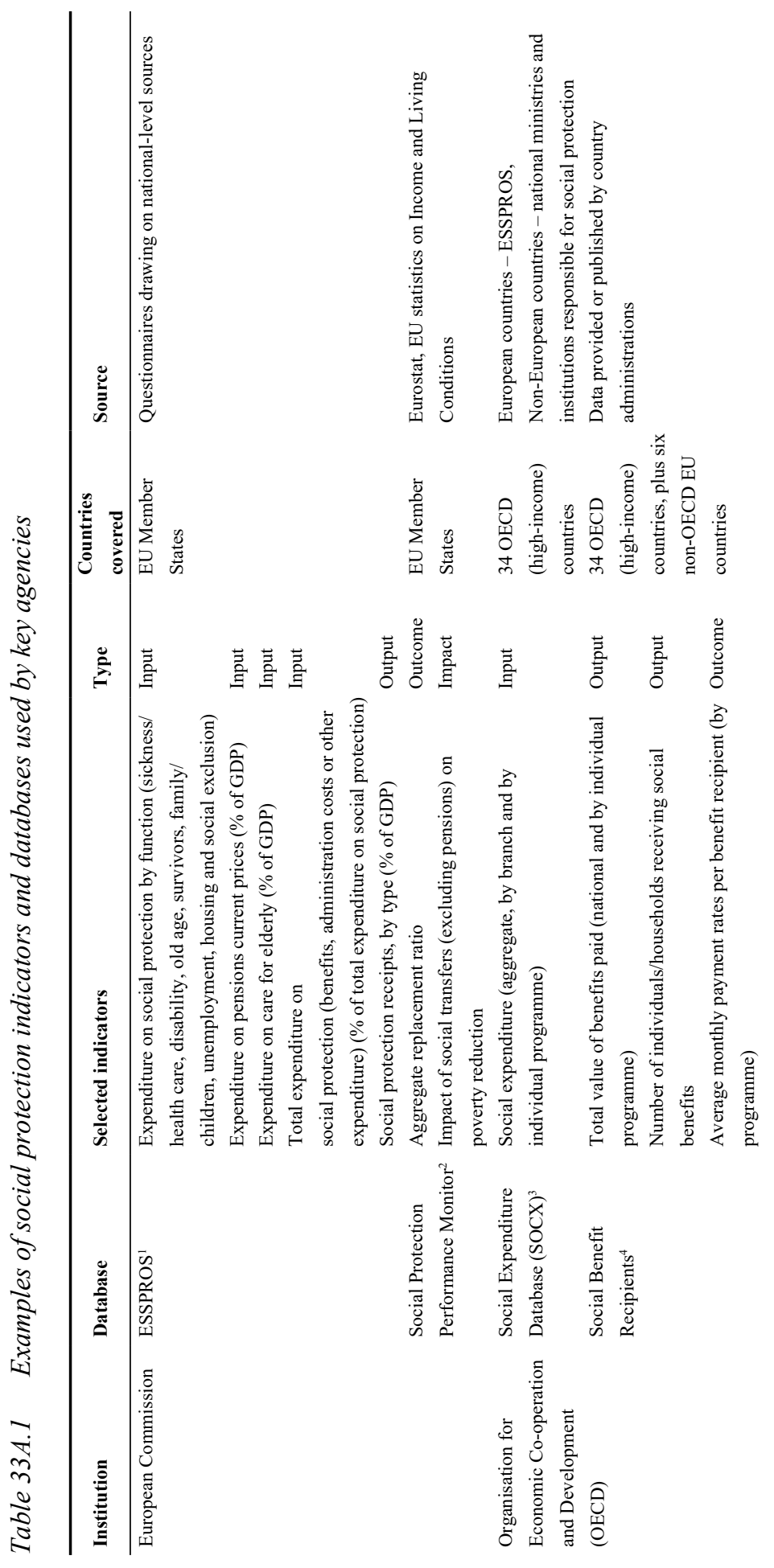



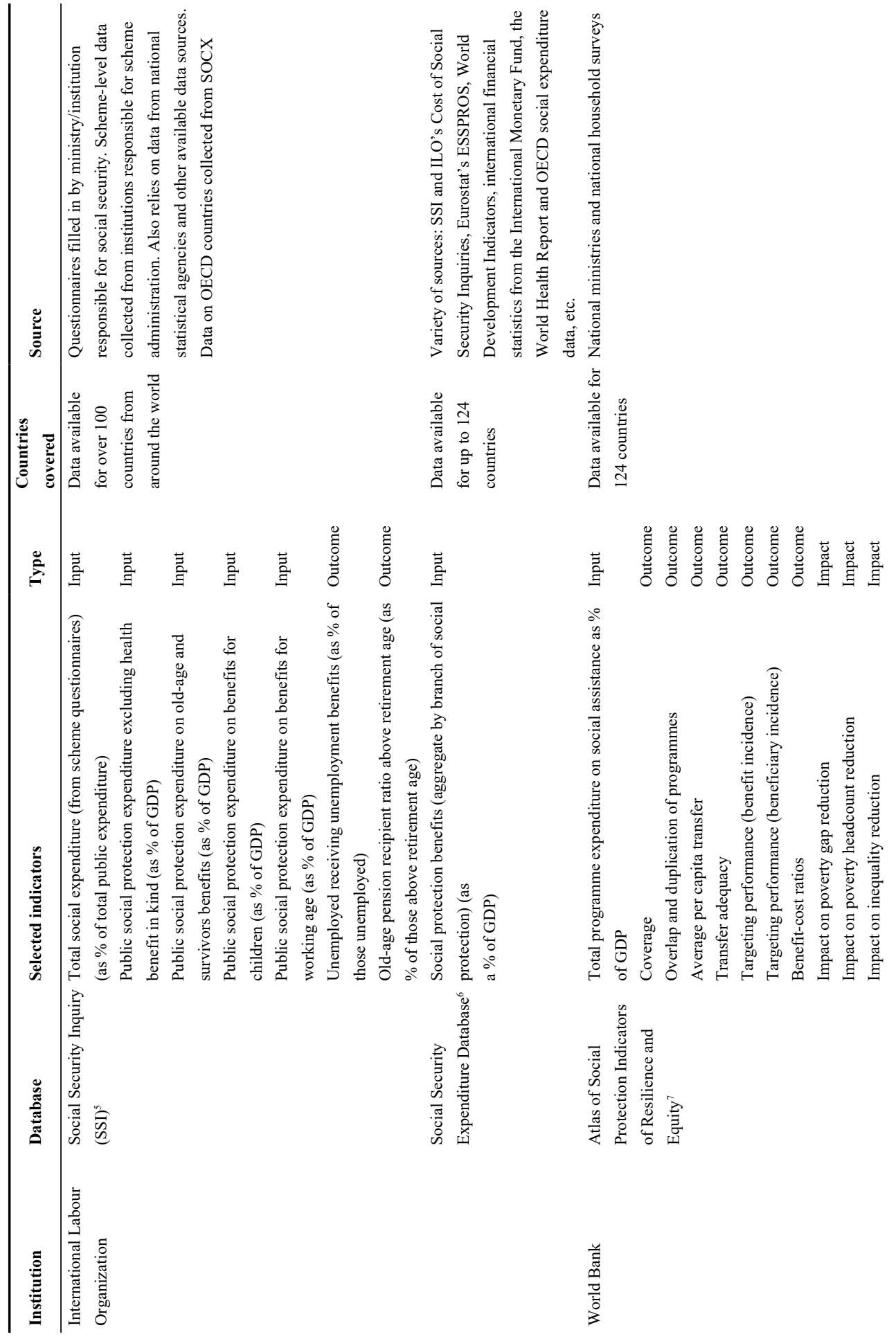


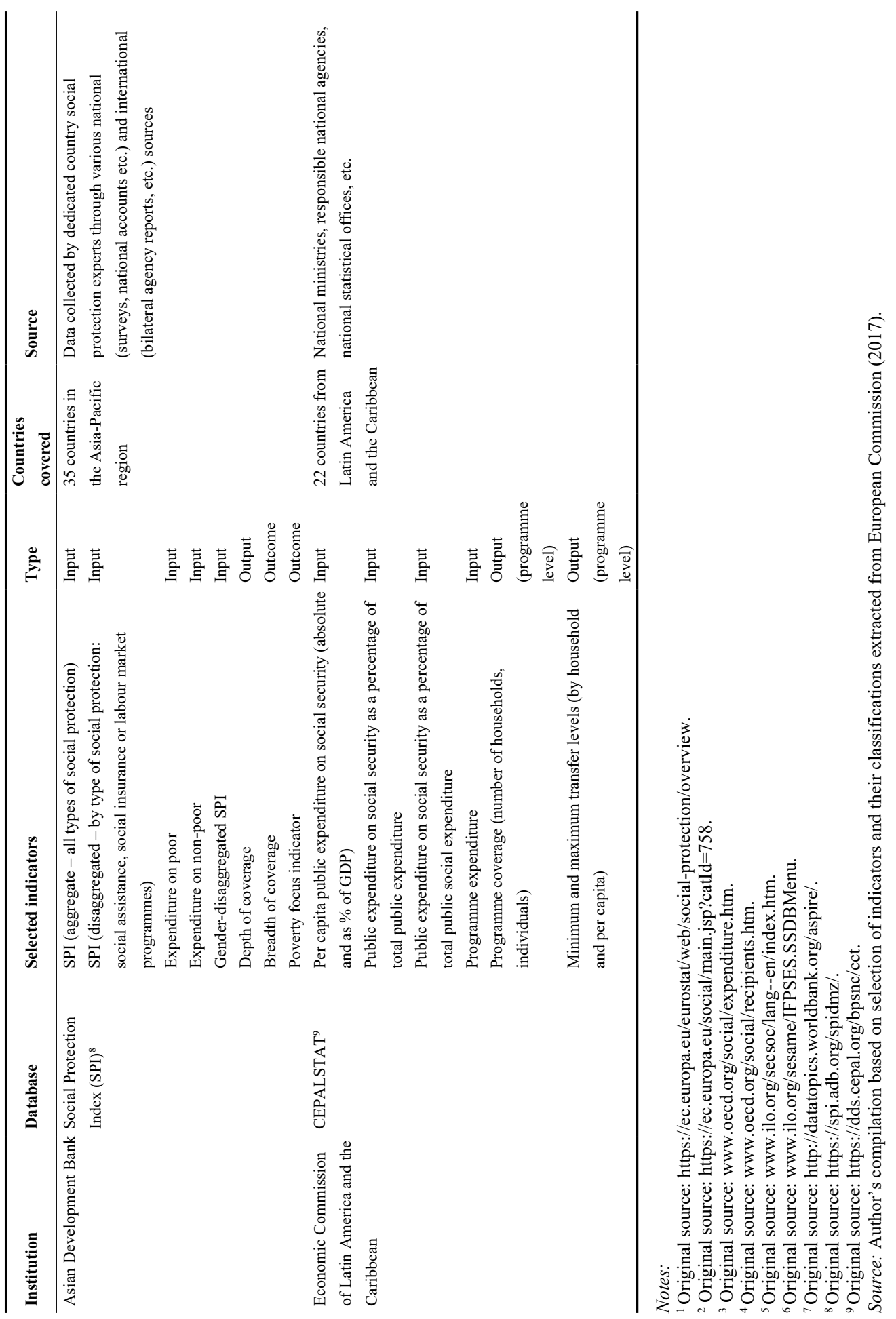

